\title{
Hydrogen Bonds between Pyrazine and HX linear Acids (X = F, NC, CN and CCH): A Theoretical Study
}

\author{
João Bosco P. da Silva*, Mário R. Silva Junior and Mozart N. Ramos \\ Departamento de Química Fundamental, Universidade Federal de Pernambuco, 50740-540 Recife-PE, Brazil
}

\begin{abstract}
Estudos teóricos usando os níveis de cálculo B3LYP e MP2 com um conjunto de base 6$31++\mathrm{G}^{* *}$ foram empregados para caracterizar complexos de hidrogênio envolvendo pirazina e ácidos lineares $\mathrm{HX}$ com $\mathrm{X}=\mathrm{F}, \mathrm{NC}, \mathrm{CN}$ e $\mathrm{CCH}$. As propriedades moleculares destes complexos e as mudanças estruturais, eletrônicas e vibracionais que ocorrem nas espécies isoladas devido à formação da ligação de hidrogênio foram calculadas e comparadas com aquelas anteriormente estimadas em complexos do tipo-T envolvendo hidrocarbonetos insaturados simples como doadores de elétrons. Nossos cálculos mostraram que estas mudanças nos complexos de Pyz...HX são muito mais pronunciadas do que aquelas verificadas nos complexos do tipo $\pi$...HX, assim como suas energias de ligação-H. Correções BSSE para as energias da ligação-H estimadas pelos cálculos B3LYP são aproximadamente três vezes menores que aquelas obtidas através dos cálculos MP2. Nossos cálculos também mostraram que ligações de hidrogênio mais fortes nos complexos Pyz...HX estão associadas com menores comprimentos de ligação-H, maiores valores de transferência de carga intermolecular e maiores deslocamentos para baixo na frequiência de estiramento H-X. A força dessas ligações de hidrogênio segue a ordem: $\mathrm{X}=\mathrm{F}>\mathrm{X}=\mathrm{NC}>\mathrm{X}=\mathrm{CN}>\mathrm{X}=\mathrm{CCH}$. Como esperado, a intensidade de estiramento H-X foi aumentada substancialmente após a formação da ligação. Finalmente, os novos modos vibracionais que surgem em decorrência da complexação foram também analisados.
\end{abstract}

Theoretical studies using the B3LYP and MP2 levels of calculation, with the 6-31++G** basis set, have been used to characterize hydrogen bonded complexes between pyrazine and HX linear acids with $\mathrm{X}=\mathrm{F}, \mathrm{NC}, \mathrm{CN}$ and $\mathrm{CCH}$. The molecular properties of these complexes and, the structural, electronic and vibrational changes that occur in the isolated species due to $\mathrm{H}$-bond formation have been calculated and then, compared with those previously obtained in T-shaped complexes, involving simple unsaturated hydrocarbons as proton acceptors. Our calculations have shown that these changes in Pyz...HX complexes are much more pronounced than those observed in the $\pi$...HX complexes, as well as their binding energies. BSSE corrections to the energy of binding-H estimated by the B3LYP results are approximately three times smaller than those obtained through MP2 results. Our calculations have also shown that stronger hydrogen bonds in the complexes Pyz...HX are associated with smaller H-bond length values, larger intermolecular charge-transfer and greater downward displacement to the stretching frequency $\mathrm{H}-\mathrm{X}$. The H-bond strength for these complexes follows the order: $\mathrm{X}=\mathrm{F}>\mathrm{X}=\mathrm{NC}>\mathrm{X}=\mathrm{CN}>\mathrm{X}=\mathrm{CCH}$. As expected, the $\mathrm{H}-\mathrm{X}$ stretching intensity was enhanced substantially after the H-bond formation. Finally, the new vibrational modes that appear due to the complexation are also analyzed.

Keywords: pyrazine, hydrogen bonds, ab initio calculations, vibrational properties, linear acids

\section{Introduction}

In the last years, we have performed ab initio molecular orbital calculations using different theoretical levels and basis sets to study molecular properties of several hydrogen-bonded complexes involving simple unsaturated hydrocarbons and HX linear acids. ${ }^{1}$ In all the complexes studied with acetylene, ethylene and cyclopropane as proton acceptors, they are near prolate asymmetric rotors with the hydrogen bond formed between

*e-mail: paraiso@ufpe.br the $\pi$ electron system of the hydrocarbon and the electrophilic hydrogen atom of the monoprotic acid. It is well known that the $\mathrm{C}-\mathrm{C}$ chemical bond in cyclopropane has appreciable electron density outwards from the C-C bonding axis, and so the electron density between its two carbons is quite different from the one in, for instance, acetylene. ${ }^{2}$ These complexes are of great chemical interest as their structures are often suggestive of intermediates whereby addition of hydrogen halides to unsaturated hydrocarbon systems proceeds. ${ }^{3}$ In our calculations, hydrogen cyanide has been used as both a proton donor 
and/or proton acceptor. As proton donors, we have also used other linear acids ( $\mathrm{HX}$ ) with $\mathrm{X}=\mathrm{F}, \mathrm{NC}, \mathrm{Cl}$ and $\mathrm{CCH}$. Our calculations have shown that the $\mathrm{H}$-bond strength in these complexes follows the order: $\mathrm{X}=\mathrm{F}>\mathrm{X}=\mathrm{NC}>\mathrm{X}=\mathrm{Cl}$ $>\mathrm{X}=\mathrm{CN}>\mathrm{X}=\mathrm{CCH}$. As expected, we have observed that stronger hydrogen bonds are associated with larger chargetransfer values and larger H-X stretching frequency downward displacements. These studies have also been useful to understand and to quantify the H-X stretching intensity enhancement after complexation. In this sense, we have employed the charge-charge flux-overlap (CCFO) model $^{4,5}$ for infrared intensities. Nowadays, it is well known that this increase in the $\mathrm{H}-\mathrm{X}$ stretching intensity is due to the charge-flux term, which is strongly affected by complexation, in contrast to what happens with the atomic charge. ${ }^{1}$

Our attention is focused on the study of the molecular properties of hydrogen-bonded complexes involving the pyrazine molecule as proton acceptor and the $\mathrm{HX}$ linear acids, with $\mathrm{X}=\mathrm{F}, \mathrm{NC}, \mathrm{CN}$ and $\mathrm{CCH}$. Pyrazine is an aromatic ring with two symmetric nitrogen atoms, which can form hydrogen bonds with HX. This H-bond essentially involves charge-transfer from the lone-pair of the nitrogen atom to the $\sigma^{*}$ antibonding orbital of HX. In this paper, we wish to evaluate the molecular properties and binding energies of these complexes as well as the structural, electronic and vibrational changes, which occur due to H-bond formation. These results will also be used to compare with those previously obtained using simple unsaturated hydrocarbons as proton acceptors.

\section{Calculations}

High level of quantum chemical calculations with electron correlation and large basis set are necessary for the proper description of a weakly bound hydrogen bonded system. These two combinations are very important in these systems to take into account the dispersion forces ${ }^{6}$ and charge transfer effects. ${ }^{1} \mathrm{DFT}^{7}$ and MP2 ${ }^{8}$ theoretical levels, for instance, can be useful to provide an easy and convenient way to include electron correlation effects in ground-state molecules at reasonable computational cost. Furthermore, it is important to use a basis set containing diffuse functions once they are necessary for the study of weak molecular interactions. ${ }^{9,10}$ Thus, we have used here the B3LYP and MP2 theoretical levels, with the 6$31++\mathrm{G}^{* *}$ basis $\operatorname{set}^{11}$, to study the molecular properties of hydrogen complexes between pyrazine and $\mathrm{HX}(\mathrm{X}=\mathrm{F}$, $\mathrm{NC}, \mathrm{CN}$ and $\mathrm{CCH}$ ). Notice that the MP2 calculations were performed using the frozen-core electron correlation approach and the basis set includes $6 \mathrm{~d}$ and $7 \mathrm{f}$ polarization functions. These calculations were performed with the GAUSSIAN 94 program. ${ }^{12}$ In this procedure, the molecular geometries of the isolated molecules and of their hydrogen complexes at the equilibrium distance were fully optimized and none of the imaginary frequency was found. We have observed that their molecular geometries are planar, except to the Pyz...HCCH complex using the MP2 calculation level. In this case, the ( $\theta \mathrm{CN}$...HC) dihedral angle between pyrazine and acetylene is slightly out-of-plane. The binding energies were computed by considering the basis set superposition error (BSSE) $)^{13}$ due to the supermolecule approach. Here, we have considered the full counterpoise method of Boys and Bernardi ${ }^{14}$ to estimate the BSSE, including the fragment deformation energy in the estimation of BSSE correction to binding energy as first highlighted by Emsley et al. ${ }^{15}$ and stressed elsewhere..$^{16,17}$ However, it is important to point out that these problems are, in general, minimized when the CP method is used in conjunction with a large basis set, which is flexible enough to provide a good description of the electrons in both the atomic core and the long-range region of the atoms. ${ }^{10,18,19}$

\section{Results and Discussions}

\section{Structural properties}

The effect of the molecular complexation on the structural properties of the isolated molecules at the B3LYP and MP2 levels of calculation using the $6-31++\mathrm{G}^{* *}$ basis set may be visualized in Table 1 .

Table 1. B3LYP/6-31++G** and MP2/6-31++G** (in parentheses) structural parameters for the Pyrazine-HX complexes with $\mathrm{X}=\mathrm{F}$, $\mathrm{NC}, \mathrm{CN}$ and $\mathrm{CCH}$

\begin{tabular}{lcccc}
\hline $\begin{array}{l}\text { Structural } \\
\text { Parameters }(\AA)\end{array}$ & $\mathrm{X}=\mathrm{F}$ & $\mathrm{X}=\mathrm{NC}$ & $\mathrm{X}=\mathrm{CN}$ & $\mathrm{X}=\mathrm{CCH}$ \\
\hline RHX & 0.967 & 1.035 & 1.087 & 1.075 \\
& $(0.961)$ & $(1.032)$ & $(1.080)$ & $(1.071)$ \\
$\mathrm{RN} \ldots \mathrm{X}$ & 2.614 & 2.834 & 3.185 & 3.346 \\
& $(2.639)$ & $(2.833)$ & $(3.199)$ & $(3.318)$ \\
$\mathrm{RNC}$ & 1.339 & 1.340 & 1.340 & 1.339 \\
& $(1.346)$ & $(1.346)$ & $(1.346)$ & $(1.346)$ \\
$\mathrm{RCC}$ & 1.397 & 1.397 & 1.398 & 1.398 \\
& $(1.397)$ & $(1.397)$ & $(1.397)$ & $(1.397)$ \\
$\mathrm{RCH}$ & 1.086 & 1.087 & 1.087 & 1.087 \\
& $(1.083)$ & $(1.083)$ & $(1.083)$ & $(1.084)$ \\
$\delta \mathrm{r}(\mathrm{H}-\mathrm{X})$ & +0.039 & +0.035 & +0.016 & +0.008 \\
& $(+0.034)$ & $(+0.032)$ & $(+0.013)$ & $(+0.007)$ \\
$\delta \mathrm{r}(\mathrm{N}-\mathrm{C})$ & +0.001 & +0.001 & +0.001 & 0.000 \\
& $(0.000)$ & $(0.000)$ & $(+0.001)$ & 0.000 \\
$\delta \mathrm{r}(\mathrm{C}-\mathrm{C})$ & -0.001 & -0.001 & -0.001 & 0.000 \\
& $(-0.001)$ & $(-0.001)$ & $(-0.001)$ & 0.000 \\
$\delta \mathrm{r}(\mathrm{C}-\mathrm{H})$ & -0.001 & -0.001 & 0.000 & 0.000 \\
& $(-0.001)$ & $(0.000)$ & $(0.000)$ & $(0.000)$ \\
\hline
\end{tabular}


We can observe that the bond lengths in Pyz...HX (X = $\mathrm{F}, \mathrm{NC}, \mathrm{CN}$ and $\mathrm{CCH}$ ) as well as the more significant structural changes occurring after complexation are predicted to be very similar to both the B3LYP and MP2 levels of calculation. The highest change observed from the B3LYP (from MP2 too) is the increase in $\mathrm{H}-\mathrm{X}$ distance in Pyz...H-X amounts until $0.04 \AA$ for $\mathrm{X}=\mathrm{F}$. The $\mathrm{N}-\mathrm{C}$ bond length in pyrazine is also increased after complexation. It is important to point out that both $\mathrm{H}-\mathrm{X}$ and $\mathrm{N}-\mathrm{C}$ are directly involved in the $\mathrm{H}$-bond formation and thus, it is expected that their bond lengths are increased after complexation. This can be seen in Table 1 through the positive sign. For instance, their B3LYP/6-31++G** values for $\mathrm{HX}$ and $\mathrm{NC}$ in Pyz...H-F are $+0.039 \AA$ and $+0.001 \AA$, respectively. It is interesting to notice that the lengthening of the $\mathrm{H}-\mathrm{X}$ bonds using the B3LYP/6-31++G** calculations are always slightly greater than the MP2 ones. For example, its B3LYP value is $+0.039 \AA$ in Pyz...HF whereas its corresponding MP2 value is $+0.034 \AA$. This elongation in the $\mathrm{H}$-X distance for the Pyz...H-X complexes is more accentuated than that previously observed in acetylene and $\mathrm{HCN}$ as proton acceptors, ${ }^{1}$ whose corresponding values are $+0.007 \AA$ and $0.011 \AA$, respectively. The latter were obtained using a MP2 level of calculation with a $6-311++\mathrm{G}^{* *}$ basis set. This same behavior is also noticed with $\mathrm{X}=\mathrm{NC}, \mathrm{CN}$ and $\mathrm{CCH}$.

On the other hand, the $\mathrm{C}-\mathrm{H}$ and $\mathrm{C}-\mathrm{C}$ chemical bonds of the aromatic ring of pyrazine are decreased upon the $\mathrm{H}$-bond formation. For example, B3LYP calculations for the $\delta \mathrm{rC}-\mathrm{H}$ and $\delta \mathrm{rC}-\mathrm{C}$ values in Pyz...H-F are equals to $0.001 \AA$. This slight decrease in the $\mathrm{C}-\mathrm{C}$ bond length is mainly due to inhibition of the lone-pair trans effect ${ }^{20}$ due to H-bond formation. The molecular complexation inhibits the charge transfer from electron lone-pair of the nitrogen atom to the $\sigma^{*}$ the antibonding orbital localized on the $\mathrm{C}-\mathrm{C}$ chemical bond, which is responsible for the elongation in the $\mathrm{C}-\mathrm{C}$ bond. Therefore, it is expected that the second complexation in pyrazine must produce a reduction still more accentuated on the $\mathrm{C}-\mathrm{C}$ bond length. In fact, B3LYP/ 6-31++G** calculations for the FH...Pyz...HF 1:2 complex show that the $\mathrm{C}-\mathrm{C}$ bond length is decreased by $-0.002 \AA$ whereas its value in Pyz...HF is $-0.001 \AA$. It is still interesting to notice in Table 1 that both the B3LYP and MP2 calculation levels indicate that the equilibrium geometry in pyrazine is indeed little affected by the nature of the proton donor molecule.

In Table 1, we can also observe that the B3LYP values for the $\mathrm{R}_{\mathrm{N} \ldots \mathrm{X}} \mathrm{H}$-bond lengths are in very good agreement with those corresponding MP2 values. We can see that these values for the Pyz...HX hydrogen bonded complexes follow the order $\mathrm{X}=\mathrm{F}<\mathrm{NC}<\mathrm{CN}<\mathrm{CCH}$. In particular, we can consider that the stability and structure for the Pyz...HX complex with $\mathrm{X}=\mathrm{CN}$ and $\mathrm{CCH}$ is predominantly determined by long-range electrostatic interactions taking into account both the structural changes (almost unchanged pyrazine geometry) due to $\mathrm{H}$-bond formation and large H-bond lengths (>3 ̊).

It is interesting to point out that the $\mathrm{R}_{\mathrm{N} . . \mathrm{X}} \mathrm{H}$-bond lengths in Pyz...HX are lower than those observed in HCN...HX obtained from MP2 calculation level with a 6$311++\mathrm{G}^{* *}$ basis set ${ }^{1}$, whose mean value is about $0.2 \AA$. For instance, its value for Pyz...HF is $2.639 \AA$ whereas its corresponding value in HCN...HF is $2.815 \AA$. On the other hand, the $\mathrm{R}_{\mathrm{N} \ldots \mathrm{F}} \mathrm{H}$-bond length in Pyz...HF of $2.639 \AA$ is very close to the one found in the pyrazine...oxalic acid complex (Pyz...OA). Belabbes and Lautié ${ }^{21}$ have found an experimental value of $2.66 \AA$ for the $\mathrm{R}_{\mathrm{N} \ldots \mathrm{O}} \mathrm{H}$-bond length in Pyz...OA through its infrared and Raman spectra investigated between 4000 and $30 \mathrm{~cm}^{-1}$. Thus, we may expect that the H-bond strength in Pyz...HF is close to that found in Pyz...OA. Belabbes and Lautié have also shown that the hydrogen bond in Pyz...OA is formed without proton transfer. So the complexation involves both the two nitrogen atoms of pyrazine and leads to the formation of N...HO hydrogen bonds.

\section{Binding energies}

Table 2 shows values of uncorrected binding energies $(\Delta \mathrm{E})$; binding energies corrected by basis set superposition error $\left(\Delta \mathrm{E}^{\mathrm{BSSE}}\right)$; binding energies corrected by zero-point vibrational contribution $\left(\Delta \mathrm{E}^{\mathrm{ZPE}}\right)$, and finally, binding energies corrected by BSSE and ZPE ( $\left.\mathrm{DE}^{\mathrm{BSSE}, \mathrm{ZPE}}\right)$. In this

Table 2. Uncorrected binding energies $(\Delta \mathrm{E})$, binding energies after BSSE correction $\left(\Delta \mathrm{E}^{\mathrm{BSSE}}\right)$, counterpoise corrections $(\mathrm{CP})$, binding energies after $\mathrm{ZPE}$ correction $\left(\triangle \mathrm{E}^{\mathrm{ZPE}}\right)$ and binding energies after BSSE and ZPE corrections ( $\triangle \mathrm{E}^{\mathrm{BSSE}, \mathrm{ZPE}}$ ) obtained from B3LYP/6$31++\mathrm{G}^{* *}$ and $\mathrm{MP} 2 / 6-31++\mathrm{G}^{* *}$ (in parentheses) calculations

\begin{tabular}{|c|c|c|c|c|c|c|}
\hline Complex & $\begin{array}{c}\Delta \mathrm{E} \\
\left(\mathrm{kJ} \mathrm{mol}^{-1}\right)\end{array}$ & $\begin{array}{c}\Delta \mathrm{E}^{\mathrm{BSSE}} \\
\left(\mathrm{kJ}^{\mathrm{mol}} \mathrm{mol}^{-1}\right)\end{array}$ & $\mathrm{CP}$ & $\mathrm{CP}^{\mathrm{MP} 2} / \mathrm{CP}^{\mathrm{B} 3 \mathrm{LYP}}$ & $\begin{array}{c}\Delta \mathrm{E}^{\text {qee }} \\
\left(\mathrm{kJ} \mathrm{mol}^{-1}\right)\end{array}$ & $\begin{array}{c}\Delta E^{\mathrm{BSSE}, \mathrm{ppe}} \\
\left(\mathrm{kJ} \mathrm{mol}^{-1}\right)\end{array}$ \\
\hline & 51.6 & 49.0 & 2.6 & & 42.4 & 39.8 \\
\hline \multirow[t]{3}{*}{ Pyz...HF } & & & & 3.2 & & \\
\hline & (51.7) & $(43.4)$ & (8.3) & & $(42.3)$ & $(34.0)$ \\
\hline & 39.5 & 36.8 & 2.7 & & 33.4 & 30.7 \\
\hline \multirow[t]{3}{*}{ Pyz...HNC } & & & & 3.1 & & \\
\hline & (46.4) & (37.9) & (8.5) & & (40.4) & (31.9) \\
\hline & 22.9 & 21.4 & 1.5 & & 18.8 & 17.3 \\
\hline \multirow[t]{3}{*}{ Pyz...HCN } & & & & 3.7 & & \\
\hline & $(27.1)$ & (21.6) & (5.5) & & $(23.0)$ & (17.5) \\
\hline & 12.7 & 10.8 & 1.9 & & 9.1 & 7.2 \\
\hline \multirow[t]{2}{*}{ Pyz...HCCH } & & & & 2.9 & & \\
\hline & (17.9) & (12.3) & (5.6) & & (13.6) & (8.0) \\
\hline
\end{tabular}


table, we also show the BSSE contributions calculated at both levels of theory.

We can initially notice that the binding energies for the Pyz...HX complexes can be ordered as: $\mathrm{X}=\mathrm{F}>\mathrm{X}=$ $\mathrm{NC}>\mathrm{X}=\mathrm{CN}>\mathrm{X}=\mathrm{CCH}$. For instance, the $\Delta \mathrm{E}^{\mathrm{BSSE}, \mathrm{ZPE}}$ values obtained from the B3LYP calculation for the Pyz...HF, Pyz...HNC, Pyz...HCN and Pyz...HCCH hydrogen complexes are $39.8 \mathrm{~kJ} \mathrm{~mol}^{-1}, 30.7 \mathrm{~kJ} \mathrm{~mol}^{-1}, 17.3$ $\mathrm{kJ} \mathrm{mol}^{-1}$ and $7.2 \mathrm{~kJ} \mathrm{~mol}^{-1}$, respectively. This order is similar to that observed in the other previously studied complexes, ${ }^{1}$ i.e., $\mathrm{C}_{2} \mathrm{H}_{2} \ldots \mathrm{HX}, \mathrm{C}_{3} \mathrm{H}_{6} \ldots \mathrm{HX}$ and $\mathrm{HCN}$...HX. Our results also show that the binding energy in Pyz...HF is much greater than that found in the T-shaped complexes involving $\pi$-electrons and HF, i.e. $\pi . . \mathrm{HF}^{22}{ }^{22}$ For instance, its $\triangle E^{\mathrm{BSSE}, Z \mathrm{PE}}$ value using the B3LYP calculation level in Pyz...HF is $39.8 \mathrm{~kJ} \mathrm{~mol}^{-1}$, whereas its corresponding values in $\mathrm{C}_{2} \mathrm{H}_{2} \ldots \mathrm{HF}, \mathrm{C}_{2} \mathrm{HF} \ldots \mathrm{HF}, \mathrm{C}_{2} \mathrm{H}_{4} \ldots \mathrm{HF}, \mathrm{C}_{4} \mathrm{H}_{2} \ldots \mathrm{HF}$ and $\mathrm{C}_{3} \mathrm{H}_{4} \ldots \mathrm{HF}$ are $11.6 \mathrm{~kJ} \mathrm{~mol}^{-1}, 7.5 \mathrm{~kJ} \mathrm{~mol}^{-1}, 11.5 \mathrm{~kJ} \mathrm{~mol}^{-1}$, $8.7 \mathrm{~kJ} \mathrm{~mol}^{-1}$ and $10.6 \mathrm{~kJ} \mathrm{~mol}^{-1}$, respectively. It is still interesting to see in Table 2 that BSSE corrections to binding energies are approximately three times lower for B3LYP than the MP2 ones, as found in other complexes. ${ }^{22,23}$

In Table 3 we show values for the binding energies corrected by BSSE and ZPE ( $\left.\Delta \mathrm{E}^{\mathrm{BSSE}, \mathrm{ZPE}}\right)$, H-bond lengths $\left(\mathrm{R}_{\mathrm{N} \ldots \mathrm{X}}\right)$ and intermolecular charge transfers ( $\Delta$ Qcorr) for the Pyz...HX complexes. $\Delta$ Qcorr represents the amount of charge transferred from the proton acceptor (pyrazine) to the proton donor molecule (HX) after complexation. It was calculated using the standard Mulliken atomic charges $\left(\mathrm{q}^{\mathrm{M}}{ }_{\alpha}\right)$ corrected by a specific overlap tensor element $\left(\Delta^{\sigma \sigma},{ }_{\text {ov }}{ }_{\alpha}\right)$ of the charge-charge flux-overlap (CCFO) modified model ${ }^{5}$ for infrared intensities:

$\mathrm{q}_{\alpha}^{\circ}=\mathrm{q}_{\alpha}^{\mathrm{M}}+\Delta_{\text {ov, } \alpha}^{\sigma, \sigma}$

where $\mathrm{q}_{\alpha}^{\circ}$ is the corrected atomic charge of $\alpha$ atom and $\sigma$ is the Cartesian axis perpendicular to the molecular plane.

Figure 1 shows the plot for B3LYP and MP2 values using the $6-31++\mathrm{G}^{* *}$ basis set of $\Delta$ Qcorr versus $\mathrm{R}_{\mathrm{N} \ldots \mathrm{X}}$ in Pyrazine...HX. We can observe that larger intermolecular charge transfers will tend to have smaller H-bond lengths for these hydrogen complexes, similarly to what was also observed in acetylene...H-X and HCN...HX. ${ }^{1}$ In particular, it is still interesting to notice in Table 3 that $\Delta$ Qcorr values are almost twice greater than those found in unsaturated hydrocarbons. For instance, the intermolecular charge transfer occurring in pyrazine-HF is 0.128 e obtained from the MP2 calculation, whereas those found in $\mathrm{C}_{2} \mathrm{H}_{2}-\mathrm{HF}^{1}$ and $\mathrm{HCN}-\mathrm{HF}^{1}$ are 0.061 e and 0.060 e, respectively.

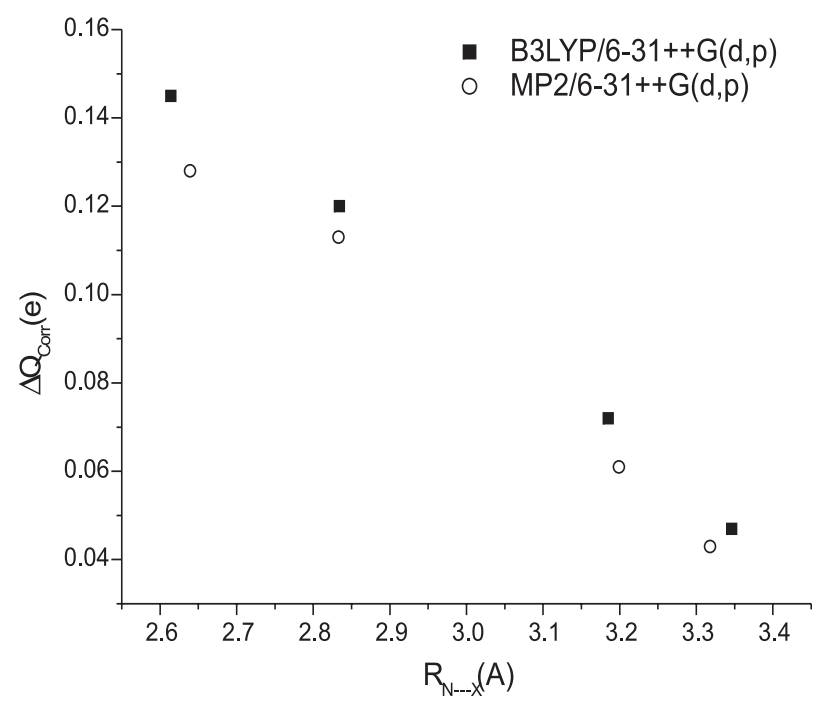

Figure 1. Variation of the B3LYP and MP2 values using the 6$31++\mathrm{G}^{* *}$ basis set for $\Delta \mathrm{Q}$ corr (e) with RN...X ( $\AA$ ) for the hydrogen-bonded complexes involving pyrazine and HX linear acids.

\section{Vibrational properties}

It is well known ${ }^{9}$ that both the calculated harmonic frequency and infrared intensity of the $\mathrm{H}-\mathrm{X}$ stretching mode are overestimated due to lack of anharmonicity correction, basis set truncation, and incomplete treatment of electron correlation. For instance, inclusion of anharmonicity effects are expected to decrease the calculated frequencies around $4 \%{ }^{24}$ bringing them closer to the experimental ones. Here, this picture is not different from that previously observed in other systems, as it can be seen in Table 4.

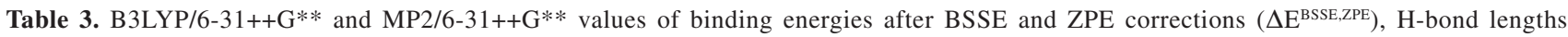
$(\mathrm{RN} \ldots \mathrm{X})$ and intermolecular charge transfers $(\Delta \mathrm{Q}$ corr). MP2 values are given in parentheses

\begin{tabular}{|c|c|c|c|c|c|c|}
\hline \multirow[b]{2}{*}{ Complex } & \multicolumn{3}{|c|}{ B3LYP } & \multicolumn{3}{|c|}{ MP2 } \\
\hline & $\begin{array}{c}\left(\Delta \mathrm{E}^{\mathrm{BSSE}, \mathrm{ZPE}}\right) \\
\left(\mathrm{kJ} \mathrm{mol}^{-1}\right)\end{array}$ & $\begin{array}{c}\text { RN...X } \\
(\AA)\end{array}$ & $\begin{array}{l}\Delta Q_{\text {corr }} \\
\text { (e) }\end{array}$ & $\begin{array}{l}\left(\Delta \mathrm{E}^{\mathrm{BSSE}, \mathrm{ZPE}}\right) \\
(\mathrm{kJ} \text { mol-1 })\end{array}$ & $\begin{array}{c}\mathrm{RN} \ldots \mathrm{X} \\
(\AA)\end{array}$ & $\begin{array}{l}\Delta Q_{\text {corr }} \\
\text { (e) }\end{array}$ \\
\hline Pyz...HF & 39.8 & 2.614 & 0.145 & 34.0 & 2.639 & 0.128 \\
\hline Pyz...HNC & 30.7 & 2.834 & 0.120 & 31.9 & 2.833 & 0.113 \\
\hline Pyz...HCN & 17.3 & 3.185 & 0.072 & 17.5 & 3.199 & 0.061 \\
\hline Pyz...HCCH & 7.2 & 3.346 & 0.047 & 8.0 & 3.318 & 0.043 \\
\hline
\end{tabular}


Table 4. Harmonic frequencies, frequency shifts, infrared intensities and intensity ratios after complexation of the HX stretching mode for the Pyz...HX complexes obtained from B3LYP/6-31++G** and MP2/6-31++G** (in parentheses) calculations. Experimental values for the isolated species are shown in brackets

\begin{tabular}{lcccc}
\hline Complex & $\begin{array}{c}v_{\mathrm{HX}}^{\text {is }} \\
\left(\mathrm{cm}^{-1}\right)\end{array}$ & $\begin{array}{c}\left(v_{\mathrm{HX}}{ }^{\mathrm{C}}-v_{\mathrm{HX}}{ }^{\text {is }}\right) \\
\left(\mathrm{cm}^{-1}\right)\end{array}$ & $\begin{array}{c}\mathrm{A}_{\mathrm{HX}} \text { is } \\
\left(\mathrm{km} \mathrm{mol}^{-1}\right)\end{array}$ & $\mathrm{A}_{\mathrm{HX}}{ }^{\mathrm{C}} / \mathrm{A}_{\mathrm{HX}}$ is \\
\hline Pyz..HF & 4068 & -842 & 114 & 13.7 \\
& $(4119)$ & $(-768)$ & $(126)$ & $(16.6)$ \\
Pyz...HNC & {$[3961]$} & & {$[77]$} & \\
& 3818 & -653 & 254 & 10.2 \\
Pyz...HCN & $33859)$ & $(-619)$ & $(257)$ & $(9.4)$ \\
& $(3514)$ & $(-203)$ & $(75)$ & 10.9 \\
& {$[3311]$} & & {$[59]$} & \\
Pyz...HCCH & 3430 & -96 & 92 & 5.1 \\
& $(3487)$ & $(-85)$ & $(89)$ & $(4.8)$ \\
& {$[3282]$} & & {$[70]$} & \\
\hline
\end{tabular}

We can observe that the B3LYP calculation for the $\mathrm{H}-\mathrm{C}$ stretching frequency in acetylene is $3430 \mathrm{~cm}^{-1}$, whereas its experimental value is $3282 \mathrm{~cm}^{-1}$. On the other hand, its corrected B3LYP value is $3293 \mathrm{~cm}^{-1}$ using a reduction of $4 \%$ to include the anharmonicity effect. We can notice that the B3LYP values for the $\mathrm{H}-\mathrm{X}$ stretching frequencies of the isolated species are in very good agreement with the MP2 ones. But, they are lower than the latter and so, they show a better agreement with the corresponding experimental values.

As expected, we can see in Table 4 that the $\mathrm{H}-\mathrm{X}$ stretching frequency is shifted downwards after complexation. These displacements obtained from B3LYP calculations are greater than the MP2 ones, similarly to what was found in the $\mathrm{C}_{2} \mathrm{H}_{2} \ldots \mathrm{HX}, \mathrm{C}_{2} \mathrm{HX} \ldots \mathrm{HX}, \mathrm{C}_{2} \mathrm{H}_{4} \ldots \mathrm{HX}$, $\mathrm{C}_{4} \mathrm{H}_{2} \ldots \mathrm{HX}$ and $\mathrm{C}_{3} \mathrm{H}_{4} \ldots \mathrm{HX}$ complexes for $\mathrm{X}=\mathrm{F}$ and $\mathrm{Cl}^{20}$ Chandra and Nguyen have also observed that B3LYP/6$31 \mathrm{G}^{* *}$ values show a better agreement with the experimental ones. Here, unfortunately, experimental values are unavaliable to our knowledge.

From Tables 3 and 4, we can also see that greater H-X downward stretching frequency displacements are associated with stronger hydrogen bonds, smaller H-bond length values and larger intermolecular charge-transfers. For instance, their B3LYP values for the strongest bounded complex, Pyz...HF, are $842 \mathrm{~cm}^{-1}, 39.8 \mathrm{~kJ} \mathrm{~mol}^{-1}, 2.614 \AA$ and 0.145 e, whereas in Pyz...HCCH, i.e., the more weakly bounded complex, their corresponding values are $96 \mathrm{~cm}^{-1}$, $7.2 \mathrm{~kJ} \mathrm{~mol}^{-1}, 3.346 \AA$ and $0.047 \mathrm{e}$, respectively. Moreover, the H-F shift in Pyz...HF is much more accentuated than those observed in $\mathrm{C}_{2} \mathrm{H}_{2} \ldots \mathrm{HF}, \mathrm{C}_{2} \mathrm{HF} \ldots \mathrm{HF}, \mathrm{C}_{2} \mathrm{H}_{4} \ldots \mathrm{HF}, \mathrm{C}_{4} \mathrm{H}_{2} \ldots \mathrm{HF}$ and $\mathrm{C}_{3} \mathrm{H}_{4} \ldots \mathrm{HF}$ for both the B3LYP and MP2 calculation levels using the $6-31++\mathrm{G}^{* *}$ basis set. ${ }^{17}$ For instance, their B3LYP values are $241 \mathrm{~cm}^{-1}, 214 \mathrm{~cm}^{-1}, 268 \mathrm{~cm}^{-1}, 191 \mathrm{~cm}^{-1}$ and $278 \mathrm{~cm}^{-1}$, respectively, whereas its corresponding value for Pyz...HF is $842 \mathrm{~cm}^{-1}$. The magnitude of this shift for the proton acceptor molecules follows the order: pyrazine $>\mathrm{C}_{3} \mathrm{H}_{4}>\mathrm{C}_{2} \mathrm{H}_{4}>\mathrm{C}_{2} \mathrm{H}_{2}>\mathrm{C}_{2} \mathrm{HF}>\mathrm{C}_{4} \mathrm{H}_{2}$, whereas for the $\mathrm{HX}$ proton donor molecule it is $\mathrm{F}>\mathrm{NC}>\mathrm{CN}>\mathrm{CCH}$. This HF shift in Pyz...HF is also greater than that found in $\mathrm{HCN}$...HF using the MP2 calculation level ${ }^{1}$, i.e., $768 \mathrm{~cm}^{-1}$ and $242 \mathrm{~cm}^{-1}$, respectively.

With respect to $\mathrm{H}-\mathrm{X}$ stretching intensity, it is increased upon H-bond formation, as it is shown in Table 4. Nowadays, it is already well known ${ }^{1}$ that this increase is due to the charge-flux term, which is strongly affected by complexation, in contrast to what happens with the hydrogen charge. This latter is always positive whereas the charge-flux is slightly negative or positive in the free molecule and becomes quite positive after complexation. In the complex, the hydrogen charge and the charge-flux term have the same algebraic sign; then, once the H-X stretching intensity is proportional to the sum of the squares of these terms, it is enormously increased upon $\mathrm{H}-$ bond formation, as it can be better seen in the expression below:

$A_{H X}^{s t r}=K\left(q_{H}^{0}+\frac{\partial q}{\partial r_{H X}} r_{H X}^{0}\right)^{2}$

where $q_{H}^{0}$ is the corrected atomic charge for the hydrogen atom at equilibrium position, $\partial q / \partial r_{H X}$ is the charge-flux due to the $\mathrm{H}-\mathrm{X}$ bond stretching obtained from the CCFOM model. ${ }^{5} r_{H X}^{0}$ is the $\mathrm{H}-\mathrm{X}$ bond length at equilibrium position and $\mathrm{K}$ is a constant that equals to $975^{1}$ for intensity values in $\mathrm{km} \mathrm{mol}^{-1}$.

From Table 4, we can observe that the $\mathrm{A}_{\mathrm{HX}}{ }^{\mathrm{C}} / \mathrm{A}_{\mathrm{HX}}{ }^{\text {is }}$ ratios obtained from the B3LYP calculations are in very good agreement with the MP2 ones. The increase of the H-X stretching intensity after complexation varies from 13.7(16.6) for Pyz...HF to 5.1 (4.8) for Pyz...HCCH, whereas MP2 values are given in parenthesis. However, there is not a clear relationship with the $\mathrm{H}$-bond strength, in contrast to what happens with the $\mathrm{H}-\mathrm{X}$ stretching frequency displacement. In order to better understand how the chargeflux term contributes to this increase on the $\mathrm{H}-\mathrm{X}$ stretching intensity, it is shown in Table 5 the B3LYP/6-31++G** values of the $\mathrm{HX}$ stretching intensities, hydrogen atomic charges and charge fluxes of HX before and after complexation with pyrazine.

We can notice that the charge-flux term $(\partial \mathrm{q} / \partial \mathrm{rHX})$ goes from $-0.022 \mathrm{e} \AA^{-1}$ in the free $\mathrm{HCN}$ molecule to $+0.580 \mathrm{e} \AA^{-1}$ after complexation, whereas the hydrogen charge $\left(\mathrm{q}_{\mathrm{H}}{ }^{\circ}\right)$ remains around $0.25 \mathrm{e}$. On the other hand, the IR spectrum of pyrazine is little affected by complexation, i.e., its 
Table 5. B3LYP/6-31++G** values of the $\mathrm{H}-\mathrm{X}$ stretching intensities and their intensity parameters before and after complexation

\begin{tabular}{|c|c|c|c|}
\hline Molecule & $\begin{array}{l}\mathrm{A}_{\mathrm{HX}} \text { 'stretching } \\
\left(\mathrm{km} \mathrm{mol}^{-1}\right)\end{array}$ & $\begin{array}{l}\mathrm{q}_{\mathrm{H}}{ }^{\circ} \\
(\mathrm{e})\end{array}$ & $\begin{array}{r}\left(\partial \mathrm{q} / \partial \mathrm{r}_{\mathrm{HX}}\right. \\
\left(\mathrm{e} \AA^{-1}\right)\end{array}$ \\
\hline $\mathrm{HF}$ & 114 & 0.447 & -0.113 \\
\hline Pyz...HF & 1566 & 0.316 & 0.984 \\
\hline $\mathrm{HNC}$ & 254 & 0.441 & 0.070 \\
\hline Pyz...HNC & 2589 & 0.335 & 1.251 \\
\hline $\mathrm{HCN}$ & 67 & 0.287 & -0.022 \\
\hline Pyz...HCN & 734 & 0.237 & 0.580 \\
\hline $\mathrm{HCCH}$ & 92 & 0.232 & 0.071 \\
\hline Pyz...HCCH & 470 & 0.193 & 0.466 \\
\hline
\end{tabular}

vibrational frequencies and intensities remain practically unaltered upon H-bond formation.

In Table 6, we can see that other two bands, which are associated with the in-plane and out-of-plane bending modes for the proton in the $\mathrm{H}-\mathrm{X}$ molecule displaced perpendicular to the $\mathrm{C}_{2}$ axis, have considerable intensities, similarly to what was also found to the acetylene...HX and HCN...HX complexes. ${ }^{1}$

It is interesting to notice that these two modes are pure rotations in $\mathrm{H}-\mathrm{F}$ and become infrared-active after complexation. The B3LYP calculations for these vibrational modes show a very good agreement with the MP2 ones. It is interesting to observe that both the calculation levels indicate that the HX out-of-plane bending intensity is always stronger than that corresponding to the $\mathrm{HX}$ in-plane bending band. For example, their B3LYP/6-31++G** values for the HX outof-plane bending intensity of Pyz...HF, Pyz...HNC, Pyz...HCN and Pyz...HCCH are $82 \mathrm{~km} \mathrm{~mol}^{-1}, 96 \mathrm{~km} \mathrm{~mol}^{-1}$, $39 \mathrm{~km} \mathrm{~mol}^{-1}$ and $75 \mathrm{~km} \mathrm{~mol}^{-1}$, respectively, whereas their corresponding values for the $\mathrm{HX}$ in-plane bending intensity are $31 \mathrm{~km} \mathrm{~mol}^{-1}, 71 \mathrm{~km} \mathrm{~mol}^{-1}, 30 \mathrm{~km} \mathrm{~mol}^{-1}$ and $63 \mathrm{~km} \mathrm{~mol}^{-1}$, respectively. It is interesting to point out that its intensity is practically dominated by the hydrogen equilibrium charge, which has positive sign. On the other hand, the inplane bending intensity also possesses important contributions due to charge-fluxes, which contribute with a negative sign, and as a consequence, its intensity is lower than that observed for the out-of-plane bending intensity.

Finally, we also show in Table 6 the intermolecular stretching mode, which is directly associated with the hydrogen bonding. As expected, it appears in the region between $50 \mathrm{~cm}^{-1}$ and $200 \mathrm{~cm}^{-1}$. Considering the previous results obtained for the acetylene...HX and HCN...HX complexes, we can expect that its B3LYP and MP2 values must have a good agreement with the experimental ones. Here, unfortunately, the latter are unknown to our knowledge. It is interesting to notice that the stretch-H frequencies also show a good linear correlation with the H-bond strength. Here the intermolecular stretching frequency obtained from the B3LYP for the strongest bounded complex, Pyz...HF, is $204 \mathrm{~cm}^{-1}$ whereas its value for Pyz...HCCH is $88 \mathrm{~cm}^{-1}$.

\section{Conclusions}

Our B3LYP and MP2 calculations using the $6-31++\mathrm{G}^{* *}$ basis set for the pyrazine....HX hydrogen complexes with $\mathrm{X}=\mathrm{F}, \mathrm{NC}, \mathrm{CN}$ and $\mathrm{CCH}$ have shown that the effects on the molecular properties of their isolated species due to H-bond formation are much more pronounced than those previously observed to the $\mathrm{HCN} \ldots \mathrm{HX}, \mathrm{C}_{2} \mathrm{H}_{2} \ldots \mathrm{HX}$, $\mathrm{C}_{2} \mathrm{HX} \ldots \mathrm{HX}, \mathrm{C}_{2} \mathrm{H}_{4} \ldots \mathrm{HX}, \mathrm{C}_{4} \mathrm{H}_{2} \ldots \mathrm{HX}$ and $\mathrm{C}_{3} \mathrm{H}_{4} \ldots \mathrm{HX}$ complexes. The structural, electronic and vibrational changes in both pyrazine and HX due to molecular complexation estimated from the B3LYP calculations are, in general, in very good agreement with those obtained from the MP2. The H-X and N-C chemical bonds, which are directly involved in the $\mathrm{H}$-bond, are increased after complexation in contrast to what happens to the $\mathrm{C}-\mathrm{C}$ and $\mathrm{C}-\mathrm{H}$ bonds in pyrazine. BSSE corrections to binding energy are much lower for B3LYP than the MP2 by a factor of $\sim 3$. Moreover, B3LYP values carry a very small BSSE correction. The H-bond strength for the Pyz...HX complexes can be ordered as: $\mathrm{X}=\mathrm{F}>\mathrm{X}=\mathrm{NC}>\mathrm{X}=\mathrm{CN}>\mathrm{X}$ $=\mathrm{CCH}$. Our calculations have also shown that stronger

Table 6. B3LYP/6-31++G** and MP2/6-31++G** values of the harmonic frequencies and infrared intensities of the HX out-of-plane and in-plane bending modes and the intermolecular stretching mode for the Pyz...HX complexes. MP2 values are shown in parentheses

\begin{tabular}{|c|c|c|c|c|c|c|}
\hline \multirow[t]{2}{*}{ Complex } & \multicolumn{3}{|c|}{ Frequency $\left(\mathrm{cm}^{-1}\right)$} & \multicolumn{3}{|c|}{ Intensity $\left(\mathrm{km} \mathrm{mol}^{-1}\right)$} \\
\hline & Out-of-plane & In-plane & Stretch-H & Out-of-plane & In-plane & Stretch-H \\
\hline \multirow[t]{2}{*}{$\overline{P y z \ldots . . . H F}$} & 911 & 1110 & 204 & 82 & 31 & 8 \\
\hline & (912) & (989) & (191) & (67) & $(57)$ & (8) \\
\hline \multirow[t]{2}{*}{ Pyz...HNC } & 968 & 989 & 147 & 96 & 71 & 10 \\
\hline & $(965)$ & $(1004)$ & (149) & (114) & (77) & (9) \\
\hline \multirow[t]{2}{*}{ Pyz...HCN } & 930 & 937 & 109 & 39 & 30 & 3 \\
\hline & $(886)$ & (909) & (113) & (28) & (33) & (2) \\
\hline \multirow[t]{2}{*}{ Pyz...HCCH } & 864 & 868 & 88 & 75 & 63 & 1 \\
\hline & $(854)$ & $(863)$ & (99) & $(85)$ & (66) & (1) \\
\hline
\end{tabular}


hydrogen bonds in Pyz...HX are associated with smaller $\mathrm{H}$-bond length values, larger intermolecular chargetransfers and greater $\mathrm{H}-\mathrm{X}$ downward stretching frequency displacements. Taking into account the $\mathrm{H}-\mathrm{X}$ downward stretching frequency shift for the $\mathrm{HCN} \ldots \mathrm{HX}, \mathrm{C}_{2} \mathrm{H}_{2} \ldots \mathrm{HX}$, $\mathrm{C}_{2} \mathrm{HX} \ldots \mathrm{HX}, \mathrm{C}_{2} \mathrm{H}_{4} \ldots \mathrm{HX}, \mathrm{C}_{4} \mathrm{H}_{2} \ldots \mathrm{HX}$ and $\mathrm{C}_{3} \mathrm{H}_{4} \ldots \mathrm{HX}$ complexes, we observe that its displacement in terms of the proton acceptor molecule follows the order: $\mathrm{Pyz}>\mathrm{HCN}$ $>\mathrm{C}_{3} \mathrm{H}_{4}>\mathrm{C}_{2} \mathrm{H}_{4}>\mathrm{C}_{2} \mathrm{H}_{2}>\mathrm{C}_{2} \mathrm{HF}>\mathrm{C}_{4} \mathrm{H}_{2}$. Moreover, it is $\mathrm{X}=\mathrm{F}$ $>\mathrm{NC}>\mathrm{CN}>\mathrm{CCH}$ for the $\mathrm{HX}$ proton donor molecule. As expected, the $\mathrm{H}-\mathrm{X}$ stretching intensity is increased upon $\mathrm{H}$-bond formation. It is increased from 5 to 15 times after complexation. The intermolecular stretching frequency shows a good linear correlation with the H-bond strength for both the B3LYP and MP2 calculation levels.

\section{Acknowledgements}

The authors wish to thank CNPq, CAPES and FINEP for partial financial support. The final form of this text was benefited by the referees' comments, which are gratefully acknowledged.

\section{References}

1. Araújo, R.C.M.U.; da Silva, J.B.P.; Ramos, M.N.; Spectrochim. Acta 1995, 51A, 821; Araújo, R.C.M.U.; Ramos, M.N.; J. Mol. Struct. (THEOCHEM) 1996, 366, 233; Araújo, R.C.M.U.; Ramos, M.N.; J. Braz. Chem. Soc. 1998, 9, 499; Lopes, K.C.; Pereira, F.S.; Araújo, R.C.M.U.; Ramos, M.N.; J. Mol. Struct. 2001, 565-566, 417; Lopes, K.C.; Pereira, F.S.; Ramos, M.N.; Araújo, R.C.M.U.; Spectrochim. Acta 2001, 57A, 1339.

2. Stevens, R.M.; Switkes, E.; Laws, E.A.; Lipscomb, W.N.; J. Am. Chem. Soc. 1971, 93, 2603.

3. Mootz, D.; Deeg, A.; J. Am. Chem. Soc. 1992, 114, 5887.

4. King, W.T.; Mast. G.B.; J. Phys. Chem. 1976, 80, 2521.

5. Gussoni, M.; Ramos, M.N.; Castiglioni, C.; Zerbi, G.; Chem. Phys. Lett. 1987, 142, 515; Gussoni, M.; Ramos, M.N.; Castiglioni, C.; Zerbi, G.; Chem. Phys. Lett. 1989, 160, 200.
6. Novoa, J.J.; Sosa, C.; J. Phys. Chem. 1995, 99, 15837.

7. Becke, A.D.; J. Chem. Phys. 1993, 98, 5648; Lee, C.; Yang, W.; Parr, R.G.; Phys. Rev. B 1988, 37, 785.

8. Moller, C.; Plesset, M.S.; Phys. Rev. 1934, 46, 618.

9. Del Bene, J.E.; Int. J. Quantum Chem., Quantum Chem. Symp. 1992, 26, 527.

10. Halkier, A.; Klopper, W.; Helgaker, T.; Jorgensen, P.; Taylor, P.; J. Chem. Phys. 1999, 111, 9157.

11. Clark, T.; Chandrasekhar, J.; Spitznagel, G. W.; Schleyer, P. v. R.; J. Comp. Chem. 1983, 4, 294.; Frisch, M. J.; Pople, J. A.; Binkley, J. S.; J. Chem. Phys. 1984, 80, 3265.

12. Frisch, M. J.; Trucks, G. W.; Schlegel, H. B. ; Gill, P. M. W.; Johnson, B. G.; Robb, M. A.; Cheeseman, J. R.; Keith, T.; Petersson, G. A.; Montgomery, J. A.; Raghavachari, K.; AlLaham, M. A.; Zakrzewski, V. G.; Ortiz, J. V.; Foresman, J. B.; Cioslowski, J.; Stefanov, B. B.; Nanayakkara, A.; Challacombe, M.; Peng, C. Y.; Ayala, P. Y.; Chen, W.; Wong, M. W.; Andres, J. L.; Replogle, E. S.; Gomperts, R.; Martin, R. L.; Fox, D. J.; Binkley, J. S.; Defrees, D. J.; Baker, J.; Stewart, J. P.; HeadGordon, M.; Gonzalez, C.; Pople, J. A.; Gaussian 94, Revision E.3, Gaussian, Inc.: Pittsburgh, PA, 1995.

13. Kestner, N.R.; J. Chem. Phys. 1968, 48, 252.

14. Boys, S.F.; Bernardi, F.; Mol. Phys. 1970, 19, 553.

15. Emsley, J.; Hoyte, O.P.A.; Overill, R.E.; J. Am. Chem. Soc. 1978, 100, 3303.

16. Turi, L.; Dannenberg, J.J.; J. Phys. Chem. 1993, 97, 2488.

17. Xantheas, S. S.; J. Chem. Phys. 1996, 104, 8821.

18. Feller, D.; J. Chem. Phys. 1992, 96, 6104.

19. Novoa, J.J.; Planas, M.; Whangbo, M.-H.; Chem. Phys. Lett. 1994, 225, 240.

20. da Costa, N.B.; Aquino, A.J.A.; Ramos, M.N.; Castiglioni, C.; Zerbi, G.; J. Mol. Struct. (Theochem) 1994, 305, 19.

21. Belabbes, Y.; Lautié, A.; Vibrational Spectrsoc. 1995, 9, 131.

22. Chandra, A.K.; Nguyen, M.T.; Chem. Phys. 1998, 232, 299.

23. Molina, J. M.; Dobado, J.A.; Daza, M.C.; Villaveces, J.L.; J. Mol. Struct. (Theochem) 2002, 580, 117.

24. Barnes, A.J.: Holroyd, S.; Spectrochim. Acta 1983, 39A, 579.

Received: November 20, 2004

Published on the web: June 22, 2005 